\title{
Modeling of THE Global and Pacific OCEANS: ON THE PATH TO EDDY-Resolving OCEAN PREDICTION
}

By Harley E. Hurlburt, Alan J. Wallcraft, Ziv Sirkes, and E. Joseph Metzger
$\mathrm{N}$ erational 1962). However, insufficient data and computing power have precluded a similar capability for the ocean despite the potential for numerous military and civilian applications, e.g.: antisubmarine warfare, tactical planning, optimum-track ship routing, search and rescue, long-range weather and climate prediction, sea-ice prediction, fisheries planning, design and protection of underwater structures such as oil rigs, and prediction of pollutant dispersion. Obstacles to prediction of ocean circulation arise because, historically, the ocean has been much more difficult to observe. In addition, the spatial scale for meandering ocean currents and eddies (the oceanic "weather") is an order of magnitude smaller than that for major weather systems and the meandering of the jet stream. It is only now that global-scale, eddy-resolving ocean prediction is at the threshold of feasibility. Four key technical or technological advances have made this possible.

1. Class VII supercomputers, like the Cray YMP8/8128, are the first capable of executing truly eddy-resolving global and basin-scale ocean models using the most efficient ocean model design available.

2. Global and basin-scale ocean models and data-assimilation techniques are being developed that can effectively utilize the expected data types. These models are designed for efficient execution on present and future supercomputers, including massively parallel machines. In the system under development by the U.S. Navy, mixed-layer models with about 20 levels in the upper $400 \mathrm{~m}$ are coupled to eddy-resolving ocean circulation

H. E. Hurlburt, Naval Research Laboratory. Stennis Space Center. MS 39529. USA. A. J. Wallcraft, Planning Systems, Inc., 115 Christian Lane, Slidell, LA 70458, USA. Z. Sirkes, Institute for Naval Oceanography, Stennis Space Center, MS 39529. USA. E. J. Metzger, Naval Research Laboratory, Stennis Space Center, MS 39529, USA. models with about 6 layers in the vertical. This is a key strategy in developing the system, because it reduces the computational requirements by two orders of magnitude.

3. Satellites provide useful data with global coverage and adequate space-time resolution and accuracy. This includes oceanic data that the models can assimilate and also includes atmospheric forcing functions. Sea-surface height (SSH) from satellite altimetry is the single most promising source of oceanic data for operational ocean prediction, because it is strongly related to subsurface thermal structure and a major component of oceanic surface currents. Other notable satellite data sources include infrared radiometers (IR), scatterometers, multichannel microwave radiometers, and ocean-color imagers. These provide information such as the location of oceanic fronts and eddies, sea-surface temperature, and surface winds and heat fluxes.

4. Another advance is improved data communications via satellite, especially shore to ship.

These topics are discussed in more detail by Hurlburt (1984, 1987) and Malanotte-Rizzoli and Hurlburt (1987). Navy interest includes depicting the present state of the ocean, a process sometimes called "nowcasting," and forecasting its future state. Skill in doing this is measured by improvement over oceanic climatology or (more common in forecasting) the improvement over a forecast of persistence (a forecast of no change). In forecasting, duration of skill is important as well as the amount of skill.

The U.S. Navy needs to provide accurate oceanic information to ships at sea. However, as explained in the papers just cited, shore-based eddy-resolving global and basin-scale systems for nowcasting and forecasting of the ocean circulation would have greater skill and potential for broader application than stand-alone, limited-area models on board ships. Hence, adequate data communication and effective data compression techniques are essential. The time scale for pre-
It is only now that

global-scale, eddy-

resolving ocean

prediction is at the

threshold of feasibility. 
. . certain oceanic

anomalies can be

nowcast and forecast

in response to

atmospheric

forcing . . . dictive skill should be much greater for oceanic than for atmospheric circulation, a month or more in the ocean versus a week in the atmosphere (e.g., see Hurlburt, 1984). Two-week skill has already been demonstrated for a relatively difficult region, the Gulf Stream, using only data for the location of oceanic fronts and eddies (Fox et al., 1992, this issue). This means that, compared with weather forecasting, data is useful as input to an ocean prediction system for a longer time after the observation was taken and that the recipient of the forecast (e.g., a ship) does not need to receive the forecast as soon after the observation time to have the forecast retain useful environmental information. It also means that a ship could extract useful information from "old" forecasts for a substantial length of time without shore communication.

The U.S. Navy has had an operational mixedlayer prediction capability since 1981 (Clancy and Martin, 1981; Clancy and Pollak, 1983; Clancy, 1992, this issue). Before having the resources needed for eddy-resolving global and basin-scale predictions of ocean circulation, the in-house Navy effort focused on eddy-resolving models of small domains, Indian Ocean models, non-eddyresolving global models, and on issues and techniques related to assimilation of satellite altimeter and IR data. The small domains have included semienclosed seas like the Gulf of Mexico (Hurlburt and Thompson, 1980, 1982), the Caribbean Sea (Heburn et al., 1982), and the Mediterranean Sea (Heburn, 1987). High-resolution modeling of small domains also has included subdomains of major ocean basins like the Gulf Stream region (Hurlburt and Thompson, 1984; Thompson and Schmitz, 1989; Thompson et al., 1992, this issue). In the Indian Ocean, $0.4^{\circ}$ resolution was sufficient to depict major current systems and eddies (Lin and Hurlburt, 1981; Kindle and Thompson, 1989). Studies using non-eddy-resolving global models have included the Florida Straits transport (Rhodes and Heburn, 1987), the Pacific to Indian Ocean exchange (Kindle et al., 1987, 1989; Murray et al., 1989, 1990), the circulation in the western equatorial Pacific (Hurlburt et al., 1989), and a model-data comparison of global SSH anomalies presented in the next section. External to the Naval Ocean Modeling Program, the global simulation with $\frac{1}{2}^{\circ}$ resolution by Semtner and Chervin (1988) is particularly notable for both the Global and Pacific Oceans. Modern supercomputers have multiple central processing units (CPUs). The Semtner-Chervin simulation was the first large ocean simulation to demonstrate execution on all CPUs simultaneously, an important capability termed parallel processing. This capability will be essential on future massively parallel supercomputers.

The data assimilation studies for satellite altimeter and IR data have investigated topics like space-time resolution and accuracy requirements, techniques for assimilation, and inference of subsurface (even subthermocline) information from sea-surface height and sea-surface temperature (Hurlburt, 1986; Kindle, 1986; Thompson, 1986; Carnes et al., 1990; Hurlburt et al., 1990). Some of these modeling and data assimilation studies helped lay the foundation for the first Gulf Stream prediction system that has demonstrated forecast skill superior to persistence at both 7 and 14 days (Fox et al., 1992, this issue). Interest in oceanic data assimilation has increased greatly in the last few years as evidenced by articles in this issue. Ghil and Malanotte-Rizzoli (1991) review the substantial body of literature that has already accumulated.

\section{A Comparison of Global Sea-Surface Height Anomalies-Model versus Satellite Altimetry}

As discussed by Hurlburt $(1984,1987)$ and Thompson et al. (1992, this issue, see Table 1), some features of the ocean circulation are a relatively direct integrated response to atmospheric forcing whereas others are not. This has an impact on data requirements. The Gulf Stream prediction system requires oceanic data input for nowcasting and forecasting because the meanders and eddies are primarily due to flow instabilities and are not a direct response to atmospheric forcing.

The non-eddy-resolving global modeling effort uses the premise that certain oceanic anomalies can be nowcast and forecast in response to atmospheric forcing, an approach discussed by Haney (1980), Busalacchi et al. (1983). Hurlburt (1984, 1987), and Cane et al. (1986). Some oceanic phenomena, such as the oceanic mixed layer, surface waves, and storm surges, are sensitive to daily fluctuations in atmospheric forcing. However, the class of anomalies considered here is a direct integrated response to atmospheric forcing on time scales much greater than the 1week time scale for atmospheric predictive skill, and these anomalies are quite insensitive to errors in representing the daily fluctuations of the weather. The U.S. Navy's geodetic Earth orbiting satellite (GEOSAT) carried a satellite altimeter capable of detecting the signature of these anomalies in the SSH. This permits a global search for this class of anomalies by comparison with an atmospherically forced global ocean model.

In November 1986, after completing the geodesy mission, GEOSAT was placed into an orbit that repeated every 17.05 days, an orbit termed the GEOSAT-ERM (Exact Repeat Mission) (Born et al., 1987). Figure 1 shows a global comparison of SSH anomalies during 20 September-7 October 1988 from repeat cycle 41 of the GEOSAT-ERM and from a non-eddy-resolving global ocean model. The GEOSAT data set was obtained from the National Oceanographic Data Center and was 
corrected for orbit error using the Goddard Earth Model (GEM-T2) gravity model (Haines et al., 1990) and software from Koblinsky et al. (1990). The orbit error was further reduced using a technique by Sirkes and Wunsch (1990).

The ocean model has two layers. The upper layer has temporally and spatially varying currents, density, and layer depth. The lower layer is infinitely deep and at rest. The interface separates layers of contrasting density and in the 2-layer configuration it represents the permanent pycnocline. The mean interface depth is $250 \mathrm{~m}$, but large deviations occur. This type of model is often called a 1.5-layer reduced gravity model, because it has two layers but only one active layer and thus it represents only the first internal vertical mode. Furthermore, because the model is infinitely deep, only gravitational acceleration reduced by buoyancy is present. With $0.5^{\circ} \times 0.7^{\circ}$ resolution (lat, long) and Laplacian "horizontal" friction using an eddy viscosity of $\mathrm{A}=2,000$ $\mathrm{m}^{2} \mathrm{~s}^{-1}$, the model is unable to resolve most eddies, although it does simulate a few eddies like the Mindanao and Halmahera eddies in the western equatorial Pacific. It was spun up from a state of rest (no motion, a flat interface, and constant density within a layer) to statistical equilibrium using the Hellerman and Rosenstein (1983) monthly wind-stress climatology, and was then continued from 1981-1989 using monthlyaveraged $1,000-\mathrm{mb}$ winds from the European Centre for Medium-Range Weather Forecasts (ECMWF). The 1981-1989 mean was replaced by the annual mean from Hellerman-Rosenstein, a procedure that reduces some of the biases found when the mean from ECMWF is used. Although the model is thermodynamic and accepts thermal forcing, relaxation to the annual mean density in the upper layer, obtained from Levitus (1982), was the only thermal forcing used and the only oceanic data assimilated. Thus, anomalies due to seasonal heating and cooling are included in the SSH field from GEOSAT but are not present in the model.

In the model, SSH was sampled along GEOSAT tracks at 3-second intervals to simulate the GEOSAT-ERM. Figure 1a shows the mean SSH from the model over the first 43 repeat cycles $(8$ November 1986-10 November 1988) of the GEOSAT-ERM and was obtained using the model GEOSAT track output. Excluding the error corrections, the simulated tracks were treated similarly to the GEOSAT data in performing an optimal interpolation to the same $1^{\circ}$ grid used for the GEOSAT anomalies. Figure $1 \mathrm{~b}$ shows the model deviation from the mean in Figure 1a for 20 September-7 October 1988 (repeat cycle 41), and Figure 1c shows the SSH deviation calculated from the actual GEOSAT-ERM for the same repeat cycle. The deviation is from the GEOSAT mean over the same period as Figure 1a. By themselves each of these anomaly pictures might

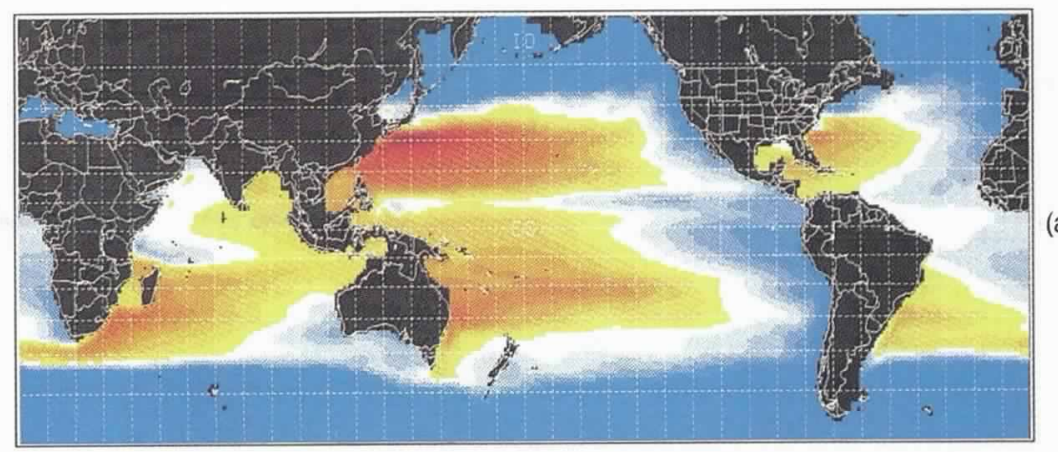

(a)
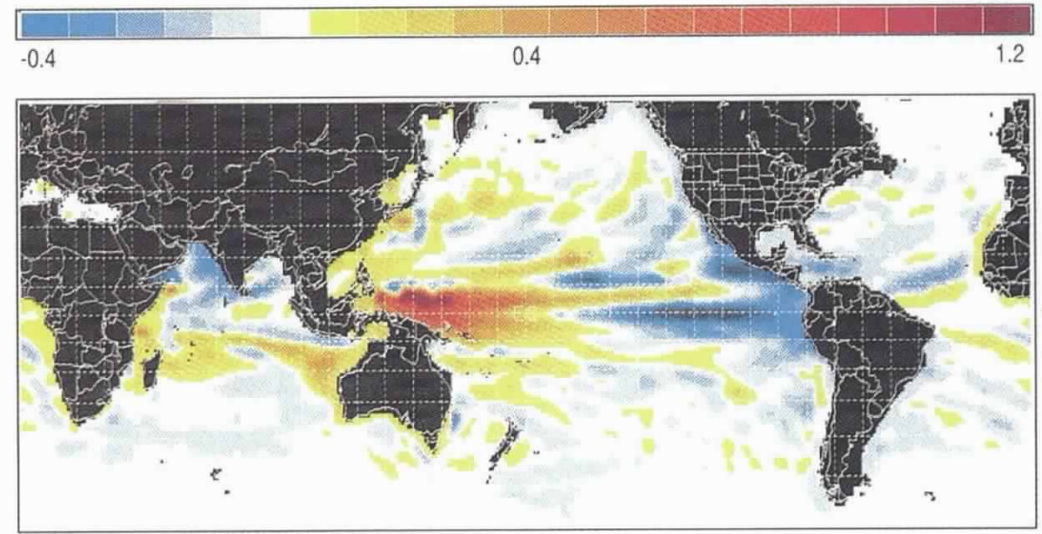

(b)

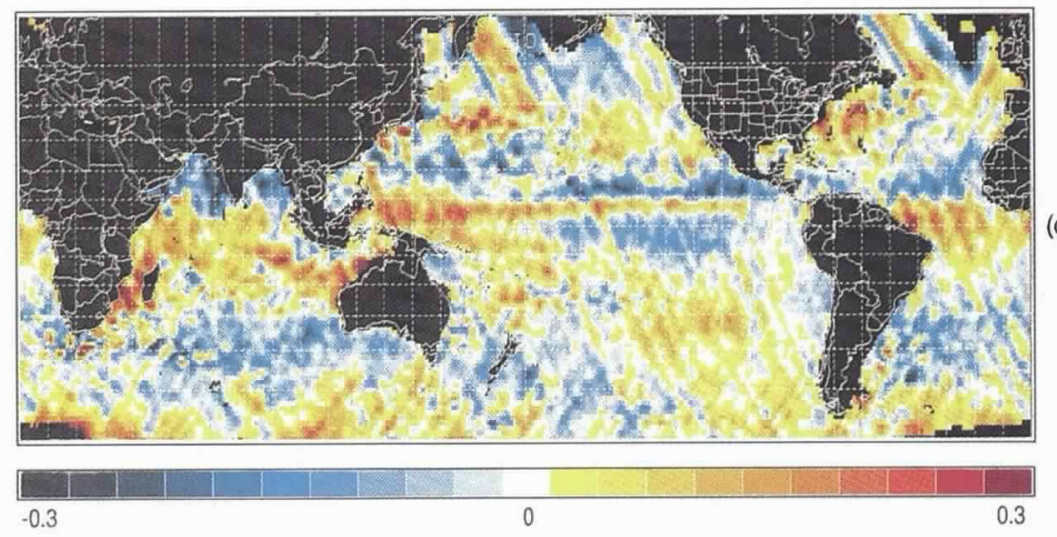

Fig. 1: (a) Mean sea-surface height (SSH) for 8 November 1986-10 November 1988 from $a \frac{1}{2}^{\circ}, 1.5$-layer global ocean model. The SSH has been interpolated to a $1^{\circ}$ grid from sampling along tracks of the Geodetic Earth Orbiting Satellite-Exact Repeat Mission (GEOSAT-ERM). (b) Model deviation from the preceding mean for 20 September-7 October 1988 (repeat cycle 41 of the GEOSAT-ERM). (c) GEOSAT-ERM SSH deviation from its mean over the same period. Color bars are in meters.

lack some credibility. The model is only 1.5 -layer reduced-gravity and is not eddy resolving. With a few small exceptions, only wind-driven anomalies are present. Thermally driven anomalies and most anomalies due to mesoscale flow instabilities are excluded. In addition, one might doubt the accuracy of the wind forcing over the data-sparse oceanic regions. The GEOSAT anomalies are open to question because of concerns about the accuracy of the data and the accuracy of the error corrections (such as those used for water vapor and orbit error). Because of the model-GEOSAT 
agreement, each enhances the credibility of the other and of the atmospheric forcing.

For example, the GEOSAT anomaly field shows a distinctive, narrow band of positive anomaly extending across most of the Pacific Ocean between $5^{\circ}$ and $10^{\circ} \mathrm{N}$. This might be dismissed as being due to water-vapor error associated with the intertropical convergence zone (ITCZ). However, the model shows the same feature as well as the negative anomalies on either side in the central and eastern Pacific. Negative sea-level anomalies are consistent with a shallowing of the thermocline and negative sea-surface temperature anomalies. In addition, the sea level in the western equatorial Pacific is relatively high and the SSH tilt along the equator is relatively large in both the model and GEOSAT. This result occurs because 1987 was an El Niño year and 1988 was an anti-El Niño year. Consistent with this pattern of anomalies, the model shows a
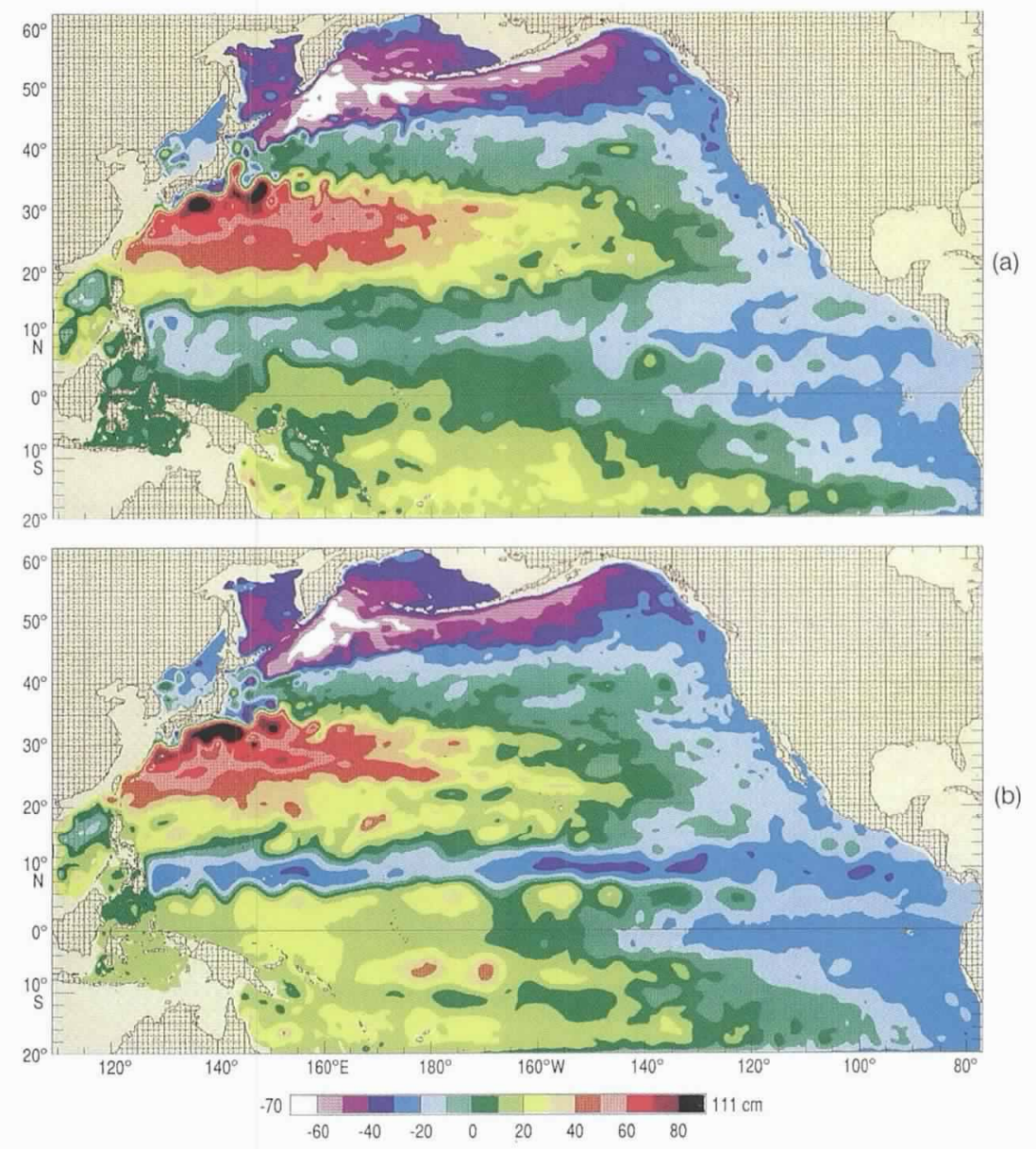

Fig. 2: Sea-surface height simulated by a $\frac{1}{8}^{\circ}$, 6-layer Pacific ocean model for (a) 17 December 1986 and (b) 16 December 1989. The model has realistic bottom topography as shown in Figure 3. Color bar is in centimeters and the extreme values labeled on the color bar are the extremes over the two dates. Meandering contours and eddies are ubiquitous, and strong interannual differences are evident. The simulation was performed on the Cray Y-MP8/ 8128 at the Naval Oceanographic Office, Stennis Space Center, MS, as part of the Naval Ocean Modeling Program. strong westward South Equatorial Current (SEC) along the equator and a northward shift in the eastward North Equatorial Countercurrent (NECC) (represented by the band of positive anomaly between $5^{\circ}$ and $10^{\circ} \mathrm{N}$ ).

Other regions where the model and GEOSAT data reveal similar anomalies are easily found, as well as regions of disagreement. The best agreement is at low latitudes where there is a relatively rapid response to changes in the wind field. However, corresponding anomalies between the model and GEOSAT are found at mid latitudes despite the model's lack of mesoscale variability and seasonal anomalies due to heating and cooling, which are relatively important at these latitudes. One example is the distribution of positive anomalies found in the Kuroshio Extension region east of Japan. Compared with the 2-year mean, the Kuroshio Current was strong south of the Japanese island of Honshu, and the Kuroshio Extension was shifted slightly to the north in the model. The $0.5^{\circ} \times 0.7^{\circ} 1.5$-layer model does not simulate the meanders and eddies, which are prevalent in the region. In an ocean prediction model with sufficiently high horizontal resolution, the SSH anomalies from satellite altimetry can be assimilated to represent the features not driven by the atmospheric forcing and to improve the accuracy of those that are. Assimilation of GEOSAT altimetry has been demonstrated for the California Current region by White et al. (1990).

Poleward of the subpolar fronts in both hemispheres, positive wind-stress curl drives an upward displacement of the interface between the two layers in the model. Vertical mixing between the layers is used to prevent the interface from outcropping at the surface. When vertical mixing occurs across a model interface, that interface is described as ventilating. In the 1.5-layer reducedgravity model, this ventilating results in the loss of wind energy to the infinitely deep abyssal layer of the model and the presence of a shallow, flat interface between the layers. As a result the model has no significant geostrophically balanced currents or anomalies within the subpolar gyres (i.e., poleward of about $45^{\circ}$ latitude).

\section{A $\frac{1}{8}^{\circ}$ Eddy-Resolving Model of the Pacific Ocean North of $20^{\circ} \mathrm{S}$}

In November 1990 a Cray Y-MP8/8128 was installed at the Naval Oceanographic Office, Stennis Space Center. This computational power made it feasible to develop $\frac{1}{8}^{\circ}$, eddy-resolving global and basin-scale ocean models using an efficient ocean model design, layered models with about 6 layers in the vertical. The plan is to couple these models to the Navy's operational mixedlayer forecast model, TOPS (Thermal Ocean Prediction System), and via TOPS to NOGAPS, the Navy Operational Global Atmospheric Prediction System (Clancy, 1992, this issue; Rosmond, 1992, 
this issue). In August 1990 in preparation for the Navy's Cray Y-MP, the Cray Y-MP8/6128 operated by the Army Corps of Engineers at Vicksburg, MS, was used to perform the first $\frac{1}{8}^{\circ}$ simulation for any major ocean basin (which had realistic topography), a $\frac{1}{8}^{\circ}$ model of the Pacific Ocean north of $20^{\circ} \mathrm{S}$. In November 1990 this model became the first user application on the Navy's Cray Y-MP8/8128.

In the layered formulation used for the Pacific model, the model equations are vertically integrated through each layer. The model is a descendant of the semi-implicit free-surface model of Hurlburt and Thompson (1980) but with extended capability (Wallcraft, 1991). It is similar to the 1.5-layer reduced-gravity model described earlier except that it is finite-depth with realistic bottom topography, thermodynamics are excluded (density is constant within a layer), greater horizontal and vertical resolution are used, and the numerical treatment of the gravity waves is implicit. Figure 2 shows two SSH snapshots from a 6-layer version of the Pacific model. The bottom topography is shown in Figure 3. The horizontal resolution is $0.125^{\circ} \times 0.176^{\circ}$ (lat, long) for each variable or about $15 \mathrm{~km}$ at mid latitudes. The model also includes all of the deep marginal seas, such as the Bering Sea, the Sea of Okhotsk, the Sea of Japan, the South China Sea, the Sulu Sea, and the Indonesian archipelago (from north to south along the western boundary). The model boundary is the $200-\mathrm{m}$ isobath with a few exceptions, such as the straits connecting the Sea of Japan. Artificial solid boundaries are placed at $20^{\circ} \mathrm{S}$ and in the straits at the southern boundary of the Indonesian archipelago. The mean interface depths are $125,275,500,750$, and $1000 \mathrm{~m}$, but large deviations from these occur in regions like the subarctic and subtropical gyres where the SSH deviations also are large. The density contrasts between the layers at these interfaces are 1.75, $0.87,0.43,0.23$, and $0.42 \mathrm{~kg} \mathrm{~m}^{-3}$, respectively. The values are means over the model domain determined using the Levitus (1982) oceanic climatology. The "horizontal" eddy viscosity is A $=100 \mathrm{~m}^{2} \mathrm{~s}^{-1}$, low enough to permit vigorous flow instabilities and numerous eddies.

The Cray Y-MP8/8128 has eight independent CPUs. The $\frac{1}{8}^{\circ}$, 6-layer Pacific model uses all eight CPUs simultaneously (parallel processing) to achieve a sustained computational rate of 1.1 billion floating point operations (adds and multiplies) per second. In this mode the model performs a 1 -year simulation in slightly $<6$ hours as measured by a clock on the wall.

Starting from rest, the model was spun up to statistical equilibrium at $\frac{1}{4}^{\circ}$ resolution using the Hellerman-Rosenstein monthly wind-stress climatology, and then continued another 15 years at $\frac{1}{8}^{\circ}$ resolution. Finally it was run 1981-1989 using monthly averaged ECMWF 1000 -mb winds

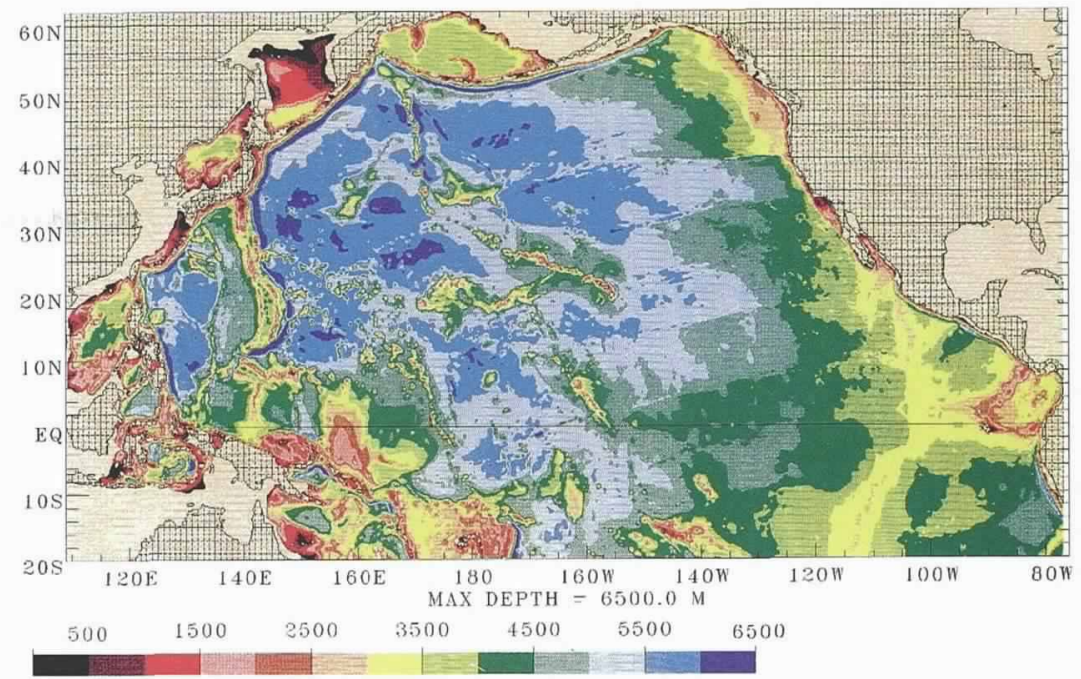

Fig. 3: $\frac{1}{8}^{\circ}$ Pacific model bottom topography. Using $6,500 \mathrm{~m}$ as a reference depth, the topographic amplitude shown here was multiplied by 0.73 to confine the topography to the lowest layer of the model. Color bar is in meters.

with the 1981-1989 mean replaced by the annual mean from Hellerman-Rosenstein. No oceanic data were assimilated in this purely wind-forced simulation.

\section{Results from the $\frac{1}{8}^{\circ}$ Pacific Simulation}

Figure 2 shows the model simulation of the SSH for 17 December 1986 and 16 December 1989. Striking features include the following: 1) the ubiquitous nature of meandering contours and eddies even though the SSH variability is high only in regions noted for strong meandering currents and eddies and 2) the interannual differences between December 1986 and December 1989, on larger scales as well as the smaller scale of individual meanders and eddies. Larger-scale anomalies are prominent in the non-eddy-resolving global model as well (Fig. 1), but they are more prominent at mid and high latitudes in the $\frac{1}{8}^{\circ}$ Pacific model. Most of the simulated meanders and eddies would, of course, not exhibit one-toone correspondence to those observed because they are due to flow instabilities. However, the current meanders and eddies are much more numerous and stronger when the model is forced by the interannually varying winds than when it is forced by the Hellerman-Rosenstein monthly wind-stress climatology. When monthly averages over 1981-1989 are formed, the amplitude of the seasonal variations in wind stress and wind-stress curl for the ECMWF 1,000 mb winds averaged over the model domain are similar to those for Hellerman-Rosenstein. This occurs when a drag coefficient of $\mathrm{C}_{\mathrm{d}}=1.5 \times 10^{-3}$ and an atmospheric surface density of $\rho_{\text {air }}=1.2 \mathrm{~kg} \mathrm{~m}^{-3}$ are used with the ECMWF winds.

Figure 2 shows the basic features of the upper ocean circulation in the equatorial and North $\mathrm{Pa}$ - include . . . the

ubiquitous nature of

meandering contours

and eddies . . .

\section{Striking features}


cific. The subtropical and subarctic gyres are clearly evident. They are separated by the Subarctic Front at $\sim 40-45^{\circ} \mathrm{N}$. However, the strongest portion of the subtropical gyre is bounded on the north by the Kuroshio Extension at $\sim 32-36^{\circ} \mathrm{N}$, giving a double frontal structure separating the strongest portion of the two gyres. Except within a few degrees of the equator, the near-surface currents tend to follow the isolines of the $\mathrm{SSH}$, with high SSH to the right in the northern hemisphere and to the left in the southern hemisphere. The stronger currents are marked by narrow ribbons of color. The subarctic gyre is bounded on the north by the Alaskan Stream off the south coast of Alaska and the south side of the Aleutian Island Chain from roughly $145^{\circ} \mathrm{W}$ to $170^{\circ} \mathrm{E}$. On the west it is bounded by the East Kamchatka Current, which flows along the coast from the western Bering Sea (starting at $60^{\circ} \mathrm{N}$ ) to the mouth of the Okhotsk Sea (at $48^{\circ} \mathrm{N}$ ) and is bounded on the southwest by the Oyashio Current southwestward from the mouth of the Okhotsk Sea, and then eastward along the narrow ribbons of color near $42^{\circ} \mathrm{N}$. South of Kodiak Island at $153.5^{\circ} \mathrm{W}$, the model's mean transport for the Alaskan Stream is $14.3 \mathrm{~Sv}$ (i.e., $14.3 \times 10^{6} \mathrm{~m}^{3} \mathrm{~s}^{-1}$ ) close to estimates from hydrography (Reed, 1984) and close to the prediction from Sverdrup flow using the annual mean Hellerman-Rosenstein wind-stress climatology.

In contrast to the Alaskan Stream, the eastern boundary currents in the subarctic gyre region undergo large seasonal fluctuations in the model. These currents flow along the eastern boundary of the model to the eastern end of the Alaskan Stream. They are strong and northward in fall and winter and are weak and southward in spring and summer. In 1986, the strongest northward flow occurred in January. Starting in February, the model simulated a series of prominent anticyclonic eddies along the coast at the beginning of the transition from northward to southward flow, the most prominent being those off Sitka, Alaska and the Queen Charlotte Islands. Later, the eddies were found between southward flow along the coast and northward flow remaining offshore. The eddies moved offshore, and a weaker series of cyclonic eddies formed shoreward before the return of northward flow along the coast. Three anticyclonic eddies that formed off Sitka, Queen Charlotte, and Vancouver Island during February-March 1986 are evident in the SSH for 17 December 1986 (Fig. 2a) at (respectively) $55^{\circ} \mathrm{N}$, $139^{\circ} \mathrm{W} ; 51^{\circ} \mathrm{N}, 135^{\circ} \mathrm{W}$; and $49^{\circ} \mathrm{N}, 132^{\circ} \mathrm{W}$. These are visible as a lighter shade of blue embedded in a darker shade of blue. South of them, cyclonic eddies are found in the region $40-50^{\circ} \mathrm{N}, 125-$ $130^{\circ} \mathrm{W}$ (visible as a darker shade of blue embedded in a lighter shade). This sequence of events and the patterns of eddies show substantial interannual variation. In 1989, the strongest northward flow in the model occurred in March, and the subsequent anticyclonic eddies were fewer and weaker. By 16 December 1989 , only one at $53^{\circ} \mathrm{N}$, $136^{\circ} \mathrm{W}$ is visible in this region (Fig. 2b).

Unlike the global model, the 6-layer Pacific model has a robust time-dependent circulation in the subarctic gyre. The interfaces between the upper layers are ventilated by positive wind-stress curl as described for the global model, but at least two of them do not ventilate over all or almost all of the gyre and a third one over a large part of it. Interior to the subarctic gyre a significant countercurrent runs roughly adjacent to the Alaskan Stream, similar to the picture by Dodimead et al. (1963) and consistent with the Sverdrup flow driven by the annual mean Hellerman-Rosenstein wind stress.

The interiors of the subarctic and subtropical gyres also contain transient fronts and frontal segments. This is particularly striking in the subtropical-gyre simulation for 16 December 1989 (Fig. 2b), where three large-scale ridges in the SSH extend eastward between $17^{\circ}$ and $32^{\circ} \mathrm{N}$. These imply alternating bands of eastward and westward flow within the subtropical gyre. There is little evidence of these in the simulation for 17 December 1986 (Fig. 2a).

The subtropical gyre is bounded on the south by the North Equatorial Current (NEC) at $\sim 10$ $18^{\circ} \mathrm{N}$. This current splits at the Philippines coast to form the northward Kuroshio Current and the southward Mindanao Current. The mean split point occurs near $14^{\circ} \mathrm{N}$. From here the Kuroshio Current flows northward along the eastern Philippines coast and then along the western boundary of the model until it separates from the coast of Japan near $35^{\circ} \mathrm{N}, 140^{\circ} \mathrm{E}$ to flow eastward as the Kuroshio Extension. The Mindanao Current flows southward along the Philippines coast from the split point to $\sim 3^{\circ} \mathrm{N}$. It is the western boundary current for an elongated gyre with the NEC on the north side and the NECC on the south side (along $\sim 5^{\circ} \mathrm{N}$ ). The gyre is marked by a trough in SSH centered at $7-9^{\circ} \mathrm{N}$. This trough and the bounding currents are much stronger in the simulation for December 1989 than in that for December 1986. In addition, the gyre is narrower and centered farther north in December 1989, but the northern boundary is farther south. Comparing December 1989 and December 1986, the eastern end of the NEC near $140^{\circ} \mathrm{W}$ is at $13^{\circ}$ versus $19^{\circ} \mathrm{N}$, and the split point at the western end is at $12.5^{\circ}$ versus $15^{\circ} \mathrm{N}$. Farther south, the $\mathrm{SSH}$ tilt along the equator and the South Equatorial Countercurrent near $9^{\circ} \mathrm{S}$ were stronger in December 1989. These results for the tropics are consistent with the El Niño present during December 1986, but may be due in part to a trend in the tropical ECMWF 1,000-mb winds.

The 6-layer model has two shallow layers. This design and vertical mixing allows the simulation 


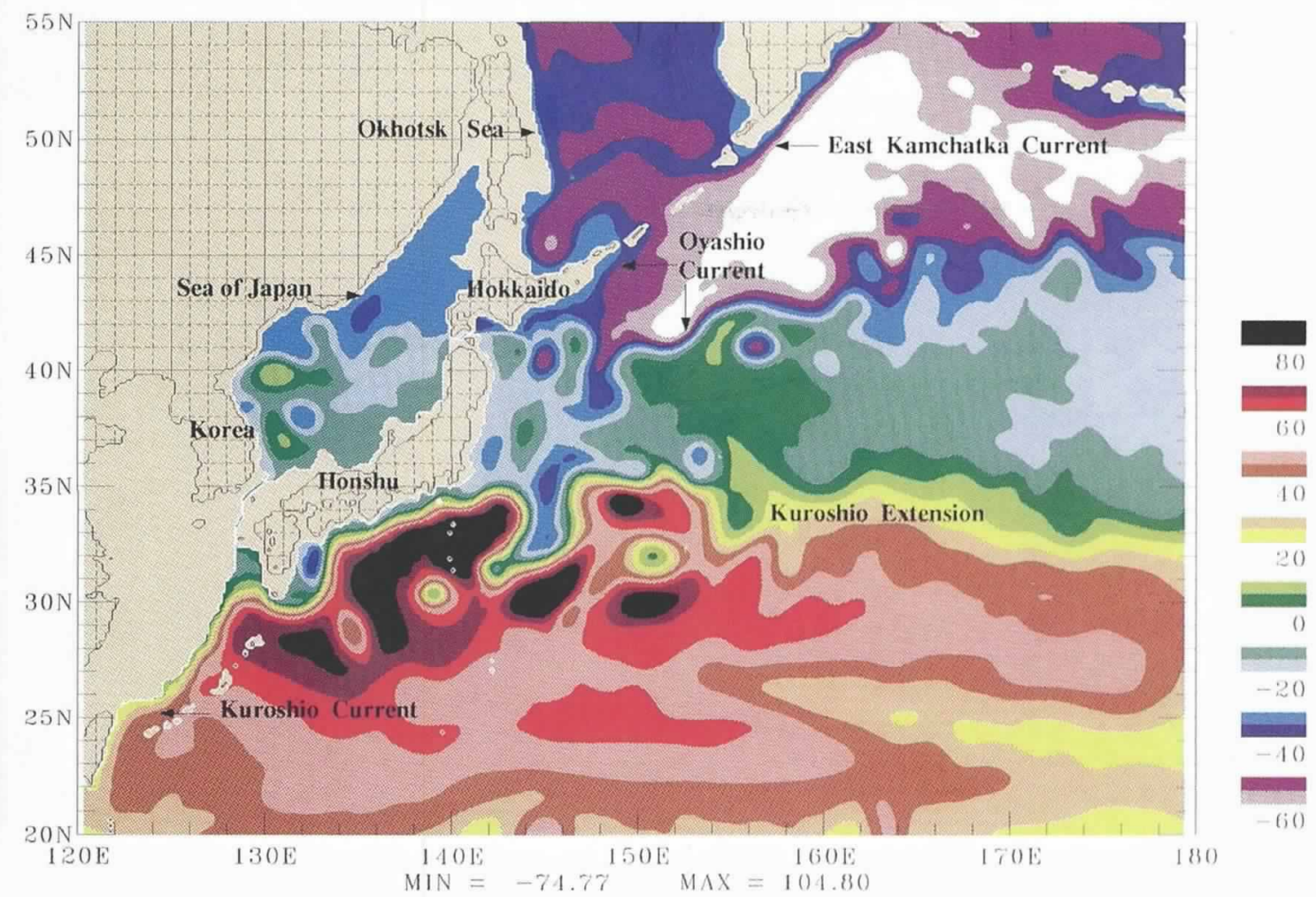

Fig. 4: Magnified view of the sea surface height in the northwest Pacific on 14 January 1983 as simulated by the $1_{8}^{\circ}$ Pacific model. The simulated meanders and eddies would not in general correspond to those observed on the same date because they are primarily due to flow instabilities. Color bar is in centimeters.

to exhibit a westward SEC at the surface and an eastward Equatorial Undercurrent (EUC) in the second layer. The behavior of the undercurrent is sensitive to the mixing depth and the choice of mean layer depths in at least two ways: the strength of the undercurrent and whether it unrealistically extends into the third layer. However, realistic behavior for the undercurrent is consistent with realistic mixing and interface depths. In this simulation the depths of the first two interfaces are slightly too shallow and/or the mixing depths too deep. As a result, the undercurrent is too strong and it extends into the third layer.

\section{The Northwest Pacific}

Figure 4 shows a magnified view of the simulated SSH in the NW Pacific for 14 January 1983. This should be used in comparison with 17 December 1986 and 16 December 1989 from Figure 2 and the composite of frontal analyses from satellite IR shown in Figure 5. In all, the northward Kuroshio Current is clearly evident along the western boundary south of Honshu, and the southward East Kamchatka Current is found along the western boundary northeast of the mouth of the Okhotsk Sea. Also evident are the Kuroshio Extension along roughly $35^{\circ} \mathrm{N}$ and

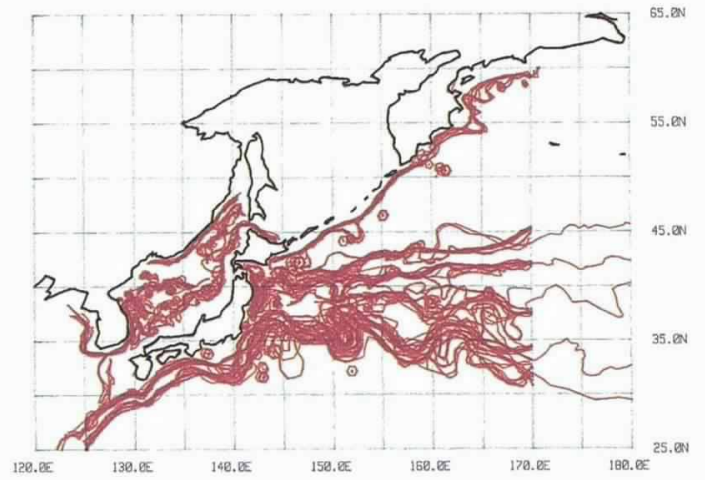

Fig. 5: Composite of oceanic frontal analyses in the northwest Pacific. These analyses are prepared routinely from satellite infrared measurements by the Operational Oceanography Center at the Naval Oceanographic Office, Stennis Space Center, MS. This composite covers 10 April-19 July 1991 at $\sim$ 3-day intervals. From $170^{\circ}$ to $180^{\circ} \mathrm{E}$ only one analysis is plotted. It shows the five frontal boundaries plotted east of Japan. From north to south they are the northern and southern boundaries of the Oyashio Current/Subarctic Front, the transition front, and the northern and southern boundaries of the Kuroshio Extension. (Courtesy Dale Ordish, Operational Oceanography Center.)
$T_{\text {he simulated }}$

meanders and eddies . . . are primarily due to flow instabilities. 
the Oyashio/Subarctic Frontal system along $40-45^{\circ} \mathrm{N}$.

One issue in this region is how the Kuroshio Current feeds part of its transport into the Subarctic Frontal region. More viscous simulations, simulations which are more linear, and simulations excluding the Sea of Japan have shown an unrealistic northward surface current along the east coast of Honshu. The eddy-resolving, strongly non-linear simulations with realistic bottom topography and an open Sea of Japan offer three more realistic alternative routes for the Kuroshio to Subarctic Front transport. The first of these is a mean transport of $2.8 \mathrm{~Sv}$ through the Sea of Japan, with two distinct branches evident in Figures 2, 4, and 5. One branch in the Sea of Japan is found along the north coast of Honshu, the other follows the Korean coast and then flows eastward across the basin at about $40^{\circ} \mathrm{N}$. The second is an inertial route that is seen near 148$150^{\circ} \mathrm{E}$. The third route is bifurcation of the Kuroshio near the Shatsky Rise, which is centered at $32.5^{\circ} \mathrm{N}, 158.5^{\circ} \mathrm{E}$ (Fig. 3). In the 6-layer simulation, this route is subsurface and is not evident in the SSH shown in Figures 2 and 4. The purely wind-driven simulation also exhibits weak meridional overturning with a net transport of $3.5 \mathrm{~Sv}$ southward across $39.5^{\circ} \mathrm{N}$ in the top two layers and compensating northward flow in the other layers. In the deeper layers, northward flow is found in the route along the east coast of Honshu.

Frontal analyses like those composited in Figure 5 are produced routinely from satellite IR by the Operational Oceanography Center at the Naval Oceanographic Office. Frontal locations from IR can be valuable input to an ocean prediction system using an eddy-resolving model like the $\frac{1}{8}^{\circ}$ 6-layer Pacific model. This information can be used to locate eddies and to fix the phase of meanders like those seen in Figures 2 and 4. In addition, they can be used to determine the location of major fronts such as the Kuroshio north wall (e.g., see Fox et al., 1992, this issue). Figure 5 clearly shows standing meanders on the Kuroshio, as does the Pacific model and the Generalized Digital Environmental Model (GDEM), the Navy's oceanic climatology (Teague et al., 1990). The GDEM climatology shows a ridge near $150^{\circ} \mathrm{E}$ that is particularly common in the model and is present on all three of the dates shown.

\section{The Western Equatorial Pacific}

Figure 6 compares the mean currents from observations and the $\frac{1}{8}^{\circ}$ 6-layer Pacific simulation during July-September 1988 in the western equatorial Pacific. Figure 6a shows observations of currents reported by Lukas et al. (1991), which were obtained from drifters drogued at a $15 \mathrm{~m}$ depth and from acoustic Doppler current profiler (ADCP) measurements. Figure 6 also shows currents from the first (b) and second (c) layers of the
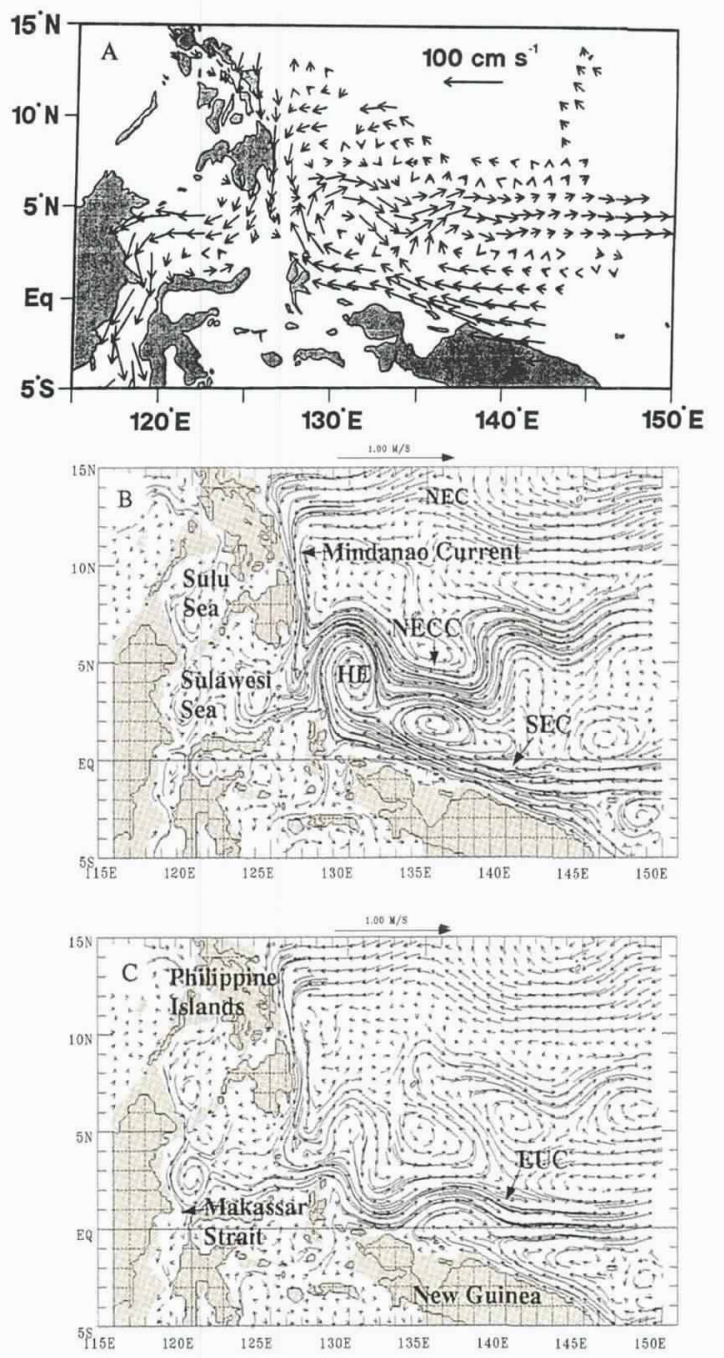

Fig. 6: (a) Drifter velocity vectors and automatic Doppler current profiler (ADCP) measurements averaged on $1^{\circ}$ squares for July-September 1988 , then smoothed (from Lukas et al., 1991). (b and c) Mean velocity vectors for July-September 1988 simulated by the $\frac{1}{8}^{\circ}$, 6-layer Pacific Model in (b) layer 1 and (c) layer 2. Layer 1 is the surface layer, layer 2 the layer containing the Equatorial Undercurrent. Velocity values from the model were sampled at 3-day intervals and then averaged in time.

model. The appropriate comparison is between the observations and the upper layer of the model. The second layer is included to show the equatorial undercurrent and the dramatic change in the currents with depth in just the upper 200-300 m.

The basic features of the flow shown by the model and the observations compare remarkably well despite the gross differences in sampling, errors in the atmospheric forcing, deficiencies in the model, and the presence of flow instabilities (which can cause two simulations using the same 
model and wind forcing to diverge in some respects, if there is any difference in the initial state). The lack of Pacific-Indian Ocean exchange is a serious deficiency in the model for this region. As a result, the Pacific model does not show the strong southward flow down the Makassar Strait (found by the drifters), a feature present in the global model discussed earlier. However, other major features in the data and the model correspond quite well. These include the southward Mindanao Current along the east coast of the Philippines and the westward SEC north of New Guinea, both of which feed into the eastward NECC that meanders along $5^{\circ} \mathrm{N}$. In addition, there is a loop into the Sulawesi Sea, which is westward on the north side and eastward on the south side. Between the SEC and the NECC, two major anticyclonic eddies are found in both the observations and the model. The well-known and quite persistent Halmahera Eddy (HE) is centered near $4.5^{\circ} \mathrm{N}, 130.5^{\circ} \mathrm{E}$ in both the model and the observational analysis during July-September 1988. Also, both show a cyclonic eddy pair elongated SE-NW north of the trough in the NECC near $135^{\circ} \mathrm{E}$. The NEC found in the model at $\sim 10-18^{\circ} \mathrm{N}$ was only sparsely sampled by Lukas et al. (1991). During July-September 1988, the model shows that the mean location of the split between the northward Kuroshio Current and the southward Mindanao Current at the Philippines coast occurs at $14.5^{\circ} \mathrm{N}$, close to the mean location found in the GDEM climatology (Hurlburt et al., 1989). Comparison with Figure 2 shows the strong variability throughout this region.

In the second layer of the model the NECC is much weaker and the Mindanao Current and the westward flow along New Guinea both feed into the eastward EUC (Fig. 6c). The second layer also shows a westward current at $3-5^{\circ} \mathrm{N}$. This current and the Mindanao Current feed into both the NECC and the EUC.

\section{Conclusions}

The articles in this issue demonstrate two major milestones on the path to eddy-resolving global ocean prediction. One is the robust demonstration of forecast skill for the Gulf Stream at both 7 and 14 days (Fox et al., 1992, this issue). The other is the $\frac{1}{8}^{\circ}$ eddy-resolving models of major ocean basins that have realistic behavior, a milestone made possible by Class VII computers like the Cray YMP8/8128. These models are also valuable tools for studying ocean circulation, a capability enhanced by the modularity of layered models. The results of these and other simulations will be discussed in greater depth in future articles, including model-data comparisons.

\section{Acknowledgements}

This is a contribution to the Global Ocean Prediction System project at the Naval Research Laboratory (NRL) under program elements
$62435 \mathrm{~N}$ and $63207 \mathrm{~N}$ and to the North Atlantic Ocean Prediction System project at the Institute for Naval Oceanography under program element $61153 \mathrm{~N}$. All of the preceding are part of the Naval Ocean Modeling Program managed by Robert Peloquin. This is also a contribution to the Eddyresolving Global Ocean Model project and the Kuroshio Extension Regional Experiment Accelerated Research Initiative at NRL, sponsored by the Office of Naval Research under program element $61153 \mathrm{~N}$. The ocean model simulations were performed on the Cray Y-MP8/8128 at the Naval Oceanographic Office, Stennis Space Center, Mississippi. We thank Ashley McManus for her work on some of the color graphics and Charles Horton at the Naval Oceanographic Office for his assistance.

\section{References}

Born, G.H., J.L. Mitchell and G.A. Heyler, 1987: GEOSAT ERM-Mission design. J. Astronaut. Sci., 35, 119-134.

Busalacchi, A.J., K. Takeuchi and J.J. O'Brien, 1983: On the interannual wind-driven response of the tropical Pacific Ocean. In: Hydrodynamics of the Equatorial Ocean. J.C.J. Nihoul, ed., Elsevier Science Publishers, Am* sterdam, 155-195.

Cane, M.A., S.E. Zebiak and S.C. Dolan, 1986: Experimental forecasts of El Niño. Nature, 321, 827-832.

Carnes, M.R., J.L. Mitchell and P.W. deWitt, 1990: Synthetic temperature profiles derived from Geosat altimetry: comparisons with air-dropped expendable bathythermograph profiles. J. Geophys. Res., 95, 17979-17992.

Clancy, R.M., 1992: Operational modeling: ocean modeling at the Fleet Numerical Oceanography Center. Oceanography. 5, 31-35.

and P.J. Martin, 1981: Synoptic forecasting of the oceanic mixed layer using the Navy's operational environmental data base: present capabilities and future applications. Bull. Am. Meteorol. Soc., 62, 770-784. and K.D. Pollak, 1983: A real-time synoptic ocean thermal analysis/forecast system. Prog. Oceanog. 12. 383-424.

Dodimead. A.J., F. Favorite and T. Hirano, 1963: Review of oceanography of the subarctic Pacific region. Int. North Pac. Fish. Comm. Bull., 13, 1-195.

Fawcett, E.B., 1962: Six years of operational numerical weather prediction. J. Appl. Meteorol., 1, 318-332.

Fox, D.N. M.R. Carnes and J.L. Mitchell, 1992: Characterizing major frontal systems: a nowcast/forecast system for the northwest Atlantic. Oceanography, 5, 49-54.

Ghil, M. and P. Malanotte-Rizzoli, 1991: Data assimilation in meteorology and oceanography. In: Advances in Geophysics, Vol. 33, B. Saltzmann, ed.. Academic Press, Orlando, FL, 141-266.

Haines, B.J., G.H. Born, J.G. Marsh and R.G. Williamson, 1990: Precise orbit computation for the Geosat exact repeat mission. J. Geophys. Res., 95, 2871-2886.

Haney, R.L., 1980: A numerical case study of the development of large-scale thermal anomalies in the central North Pacific Ocean. J. Phys. Oceanogr., 10, 541-556.

Heburn, G.W., 1987: The dynamics of the Western Mediterranean Sea: A wind forced case study. Annales Geophysicae, 5B, 61-74.

, T.H. Kinder. J.H. Allender and H.E. Hurlburt, 1982: A numerical model of eddy generation in the southeastern Caribbean Sea. In: Hydrodynamics of Semi-Enclosed Seas. J.C.J. Nihoul. ed., Elsevier Scientific Publishing Company, Amsterdam. 299-327.

Hellerman, S. and M. Rosenstein, 1983: Normal monthly wind stress over the world ocean with error estimates. J. Phys. Oceanogr., I3, 1093-1104.
. . $\frac{1}{8}^{\circ}$ eddy-resolving

models of major ocean

basins that have

realistic behavior, a

milestone. . . 
Hurlburt, H.E., 1984: The potential for ocean prediction and the role of altimeter data. Mar. Geod., 8, 17-66.

, 1986: Dynamic transfer of simulated altimeter data into subsurface information by a numerical ocean model. J. Geophys. Res., 91, 2372-2400.

, 1987: The ocean prediction problem and its diversity: some issues and possible solutions. In: Ocean Prediction Workshop 1986, C.N.K. Mooers, A.R. Robinson and J.D. Thompson, eds., Oceanographer of the Navy, Washington, DC and Office of Naval Research, Arlington, VA, 192-226.

, D.N. Fox and E.J. Metzger, 1990: Statistical inference of weakly correlated subthermocline fields from satellite altimeter data. J. Geophys. Res., 95, 1137511409.

, J.C. Kindle, E.J. Metzger and A.J. Wallcraft, 1989: Results from a global ocean model in the western tropical Pacific. In: Proceedings of the Western Pacific International Meeting and Workshop on TOGA COARE. J. Picaut, R. Lukas, and T. Delcroix, eds., Centre ORSTOM de Noumea, New Caledonia, 343-354.

and J.D. Thompson, 1980: A numerical study of Loop Current intrusions and eddy shedding. J. Phys. Oceanogr., 10, 1611-1651.

and J.D. Thompson, 1982: The dynamics of the Loop Current and shed eddies in a numerical model of the Gulf of Mexico. In: Hydrodynamics of Semi-Enclosed Seas, J.C.J. Nihoul, ed., Elsevier Scientific Publishing Company, Amsterdam, 243-297.

and J.D. Thompson, 1984: Preliminary results from a numerical study of the New England Seamount Chain influence on the Gulf Stream. In: Predictability of Fluid Motions, G. Holloway and B.J. West, eds., American Institute of Physics, New York, 489-504.

Kindle, J.C., 1986: Sampling strategies and model assimilation of altimetric data for ocean monitoring and prediction. J. Geophys. Res., 91, 2418-2432.

, G.W. Heburn and R.C. Rhodes, 1987: An estimate of the Pacific to Indian Ocean throughflow from a global numerical model. Further Progress in Equatorial Oceanography, E.J. Katz and J.M. Witte, eds., Nova University Press, Ft. Lauderdale, FL, 317-321.

, H.E. Hurlburt and E.J. Metzger, 1989: On the seasonal and interannual variability of the Pacific to Indian Ocean throughflow. In: Proceedings of the Western $\mathrm{Pa}$ cific International Meeting and Workshop on TOGA COARE. J. Picaut, R. Lukas and T. Delcroix, eds.. Centre ORSTOM de Noumea, New Caledonia, 355365.

and J.D. Thompson, 1989: The 26- and 50-day oscillations in the western Indian Ocean: Model results. J. Geophys. Res., 94, 4721-4736.

Koblinsky, C., J.G. Marsh, B. Beckley, A. Brenner and R. Williamson, 1990: Geosat orbit replacement software for altimeter geophysical data records. GEM-T2 ephemerides for November, 1986 to November. 1988 (unpublished manuscript with the software)

Levitus, S., 1982: Climatological atlas of the world ocean. NOAA Professional Paper 13, Geophysical Fluid Dynamics Laboratory, Princeton, NJ, $173 \mathrm{pp}$.

Lin, L.-B. and H.E. Hurlburt, 1981: Maximum simplification of nonlinear Somali Current dynamics. In: Monsoon Dynamics, M.J. Lighthill and R.P. Pearce, eds., Cambridge University Press, 541-555.
Lukas, R., E. Firing, P. Hacker, P.L. Richardson, C.A. Collins, R. Fine and R. Gammon, 1991: Observations of the Mindanao Current during the Western Equatorial $\mathrm{Pa}-$ cific Ocean Circulation Study. J. Geophys. Res., 96, 7089-7104

Malanotte-Rizzoli, P. and H.E. Hurlburt, 1987: Report of working group IV on global prediction systems. In: Ocean Prediction Workshop 1986, C.N.K. Mooers, A.R. Robinson and J.D. Thompson, eds., Oceanographer of the Navy, Washington, D.C. and Office of Naval Research, Arlington, VA, 129-158.

Murray, S.P., D. Arief, J.C. Kindle and H.E. Hurlburt, 1990: Characteristics of circulation in an Indonesian archipelago strait from hydrography, current measurements and modeling results. In: The Physical Oceanography of Sea Straits, L.J. Pratt, ed., Kluwer Academic Publishers, Boston, MA, 3-23.

Murray, S.P., J.C. Kindle, D. Arief and H.E. Hurlburt. 1989: Comparison of observations and numerical model results in the Indonesian throughflow region. In: Proceedings of the Western Pacific International Meeting and Workshop on TOGA COARE. J. Picaut, R. Lukas and T. Delcroix, eds.. Centre ORSTOM de Noumea. New Caledonia, 145-154.

Reed, R.K., 1984: Flow of the Alaskan Stream and its variations. Deep-Sea Res., 31, 369-384.

Rhodes, R.C. and G.W. Heburn, 1987: Numerical simulation of wind-forced seasonal and interannual transport variability through the Florida Straits. In: Ocean Prediction Workshop 1986, C.N.K. Mooers, A.R. Robinson and J.D. Thompson, eds., Oceanographer of the Navy, Washington, D.C. and Office of Naval Research, Arlington, VA, 485-486.

Rosmond. T., 1992: NOGAPS/TOPS: A prototype fully-coupled ocean-atmosphere prediction system. Oceanography, 5. 25-30.

Semtner, A.J. and R.M. Chervin, 1988: A simulation of the global ocean circulation with resolved eddies. J. Geophy's. Res., 93, 15502-15522.

Sirkes. Z. and C. Wunsch. 1990: Note on apparent systematic and periodic errors in GEOSAT orbits. Geoph's. Res. Let. 17. 1307-1310.

Teague, W.J., M.J. Carron and P.J. Hogan. 1990: A comparison between the Generalized Digital Environmental Model and Levitus climatologies. J. Geophys. Res., 95, 71677183.

Thompson, J.D., 1986: Altimeter data and geoid error in mesoscale ocean prediction: some results from a primitive equation model. J. Geophys. Res., 91, 2401-2417. - and W.J. Schmitz, Jr., 1989: A limited-area model of the Gulf Stream: Design and initial experiments. $J$. Phys. Oceanogr., 19, 791-814.

_ T.L. Townsend and W.J. Schmitz, Jr., 1992: Ocean prediction and the Atlantic Basin: Scientific issues and technical challenges. Oceanography, 5, 36-41.

Thompson, P.D., 1961: Numerical Weather Analysis and Prediction. MacMillan, New York, 170 pp.

Wallcraft, A.J., 1991: The Navy Layered Ocean Model users' guide. NOARL Report 35. Stennis Space Center, MS, $21 \mathrm{pp}$.

White, W.B., C.-K. Tai and W.R. Holland, 1990: Continuous assimilation of Geosat altimetric sea level observations into a numerical synoptic ocean model of the California Current. J. Geophys. Res., 95, 3127-3148. 